\title{
Re-dispatch and Application of FACTs for Transactions Allocation in Deregulated Electricity Markets
}

\author{
ARCHANA JAISINGPURE, V. K. CHANDRAKAR, R. M. MOHRIL \\ Department of Electrical Engineering, RTM Nagpur University \\ Nagpur, INDIA
}

\begin{abstract}
In the current scenario, transmission cost allocation is one of the significant difficulties arises due to the expansion in power exchanges in transmission open access looked by electric energy area. The proposed method calculates transmission cost allocation by considering bilateral \& multilateral transactions. The transmission cost allocation approach in the proposed method derives from equivalent bilateral which states that a small amount of every generator provides with each request in consistently and separated manner. The influence of power flow in network via all lines due to a transaction is measured by power flow solution. This paper discusses the congestion problem in the deregulated electricity market using an optimal power flow (OPF). The transmission lines are uncongested using re-dispatch method and then taxes are calculated for the establishment of the flexible A.C. transmission systems (FACTS) devices in the transmission network to reduce taxes. The excellent location of FACTS device can be identified by the bus on which highest $\mathrm{T}$. The result indicates that the combination of TCSC and SVC incredibly discount the measure of re-dispatched power which provides optimal operating point nearer to the market settlement. Hence, TCSC and SVC gives convenient option to block the execution of transmission estimation utilizing approaches and calculate the transmission price.
\end{abstract}

Key-Words: Congestion Management, FACTS devices, OPF, Transmission Pricing, TCSC, electricity market

Received: August 3, 2020. Revised: November 17, 2020. Accepted: December 13, 2020. Published: December 31, 2020.

\section{Introduction}

The tremendous advancement in airways and telecommunication industries, electric utilities have adopted the idea of deregulation. From last few decades, transmission and dissemination authorities are vertically coordinated for government irrespective of expenditure and revenue from operation of power system. Deregulation of power system is generally defined as reformation of system and fiscal incentives organized by government to run power industries [1]. The open access to the power system in terms of power generation and distributions arises a tight competition in the cooperate market. Different organizations in the market generate, transmit and distribute the power at very competitive prices. The idea of enhancing operations with respect to expenditure and revenue are the important part which the organization can trust [2]. The contract is made in advance to maintain coordination among generation and distribution companies.

During the power delivery implementation, it is important to analyze transmission loading patterns may vary with the proposed patterns. Transmission system operator (TSO) need to assure the proper open admittance for transmission administrations to all members of operational market [3]. Sometimes, congestion may occur in transmission network when producers and consumers of electricity have a tendency to exchange power beyond the operation limit. A Congestion management [4-5] plays core role in transmission system to avoid violation of operation limit. The Transmission cutoff points may relate either to a part of gears that limit points power stream in actual terms, or to operational furthest reaches that can neglect. Transmission limits may relate either to a part of equipment that reduces power flow in physical terms, or to operational limit that can disobey. Violating transmission constraints reflects in the businesses of the power network in a diversity of the cost of electrical power [6-8]. The primary objective is to control generator output so that the system remained stable with no limit violation and at the least cost. However, in a deregulated environment, the objective is to set up a set of rules that provides sufficient supervision over manufacturers and users to support an adequate standard of a power system in both limited (realtime application) terms and long (transmission and generation system) while maximizing market productivity [9-11]. We could treat congestion in a transmission scheme in several respects such as. 


\section{- $\quad$ Load Shifting. \\ - Generation Re-dispatch. \\ - Contracts curtailment.}

Flexible AC transmission systems (FACTS) are a recent technology started in last two decades, and practice over the world. The IEEE presents FACTS as a power electronic-based system and other stationary equipment that can improve controllability, build power transmission efficiency [12]. Presently, power producers and system operators all over the world face growing needs for bulk power transmission, reasonable-cost power distribution and greater accuracy, to some measure; such issues are being relieved by the growing technology of FACTS [13]. We could connect FACTS either in series or in shunt with the power system or indeed in an associated pattern to give compensation for the power system. Variable series capacitors, phase shifters and consolidated power flow controllers as the most needed. The efficiency of TCSC installation in a congested transmission system to build up energy flow criteria and to support location marginal prices at fair standards is verified FACTS devices can be employed to reduce the power flow which arises in many benefits like losses diminished [14], stability margin increased etc. Because of such factors of FACTS, incorporating it into the congestion management becomes further and further prominent. Fast power flow management is the central function of FACTS devices, which can serve to bring about the above intentions [15]. FACTS devices regulate the system by switching or controlled shunt compensation, series compensation, or phase shift control. These devices produce a further adaptation to changing operational conditions and increase the management of existing systems. Thyristor-Controlled Series Capacitor (TCSC) and Static Var Compensator (SVC) are two mainly emerging FACTS devices that flexibly control line impedance and susceptance, separately [16-17]. We have used TCSC and SVC in this study to develop energy security margin and line congestion alleviation.

Figure 1 lists the suitable methods employed in CM. The light-shaded methods are consistently regarded as remedial methods, which let the market function as if there are no restraints and allow it to the TSO to accept actions to protect system surveillance. By increasing the cost of the congested part of the network to weaken traffic to alleviate the overpopulation, the heavy-shaded methods are so called pricing methods.

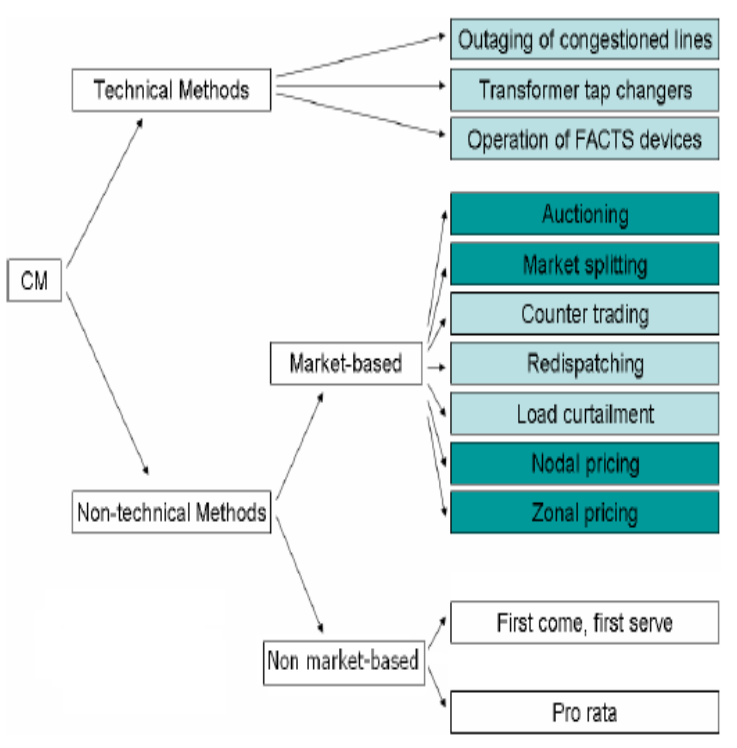

Fig.1 Congestion management methods

All results of congestion situations vary in their manner. They all show a limited solution to the market issue, which would not be acceptable to as a great- term solution. Transmission expansion in a faster expanding environment would be a bold solution if it is accompanied with an economic gain that would appeal to lenders. Moreover, system reliability and surveillance would be built up as the system increases. In the proposed work re-dispatch technique is employed to cut down the congestion. Re-dispatch technique as a low-cost approach can be employed as a solid solution for development of excellent power flow problem by incorporating FACTS devices and diminishing the congestion and taxes. In this study, a remedial solution for congestion control by using TCSC AND SVC has been discussed. The FACTS devices aid the system congestion relief while taxes are decreased progressively as easily as transmission losses reduces. Analyzing the results with and without FACTS devices confirms that these devices are useful for great time congestion control and diminishing the taxes. The transmission services pricing issue has been an interesting ongoing field of investigation. One of the most popular method for transmission pricing is the postage stamp method, which gives the correct cost for providing energy regardless of the distance and power track. This method retrieves the transmission cost. The MW-Mile method is a pricing procedure that can examine the actual state of power System. In this way, transmission cost is designated based on extent 
of operation of the transmission grid by each purchaser.

\section{Algorithm for Congestion Management}

Nevertheless, because of transmission line capacity constraint, any generators cannot increase and deliver power to the consumers. We can define this condition as congestion. When low-cost generator is constricted to provide its power, the higher cost per unit will increase generation to match the load requirement. In this condition, total generation cost goes up and civil interest will be decreased. Recently, there has been increasing concern in dealing with congestion control using FACTS devices. Effects of these devices' service in increasing load capability and removing congestion [8]. In solving congestion problem using FACTS devices, both industrial and cost-effective applications have to be organized. Adequate data should hold these studies, i.e. positions of FACTS devices, generation cost. For that infer, this study introduces an approach which can provide best possible solutions relating those data. Having these solutions, one can make the strongest solutions for an effective utilization [9]. We have implemented this approach to deal with power system issue. This study concentrates on FACTS allocation for congestion control. Then, IEEE 30 bus is needed to check the recommended method. The initial objective is to reduce generation cost, and to put the line flow within the transmission system capacity set to avoid transmission congestion. The second objective is to drop the taxes by using FACTS devices an SVC and the third objective is to determine transmission pricing techniques [10-11]. The benefit obtained from FACTS is considered as the distinction between taxes with FACTS and without FATCS. The costs are measured for each line and we illustrate procedure in fig. 1.

\subsection{Re-dispatching}

The market is achieved without the restraints of the transmission system. If the congestion arises, the ISO re-dispatches and achieves in such a manner that congestion diminishes. This will lead to the ISO purchasing power from excessive cost ranges. The generators in the nominal cost ranges will be called for to adjust downwards. Since the ISO is purchasing power at an excessive cost and closing it at a cheaper cost, it acquires a cost. The net cost obtained by the ISO is a manifestation of the congestion charge and is a warning for finance. The ISO directly commands generators to up control or down regulate without the value of the market.

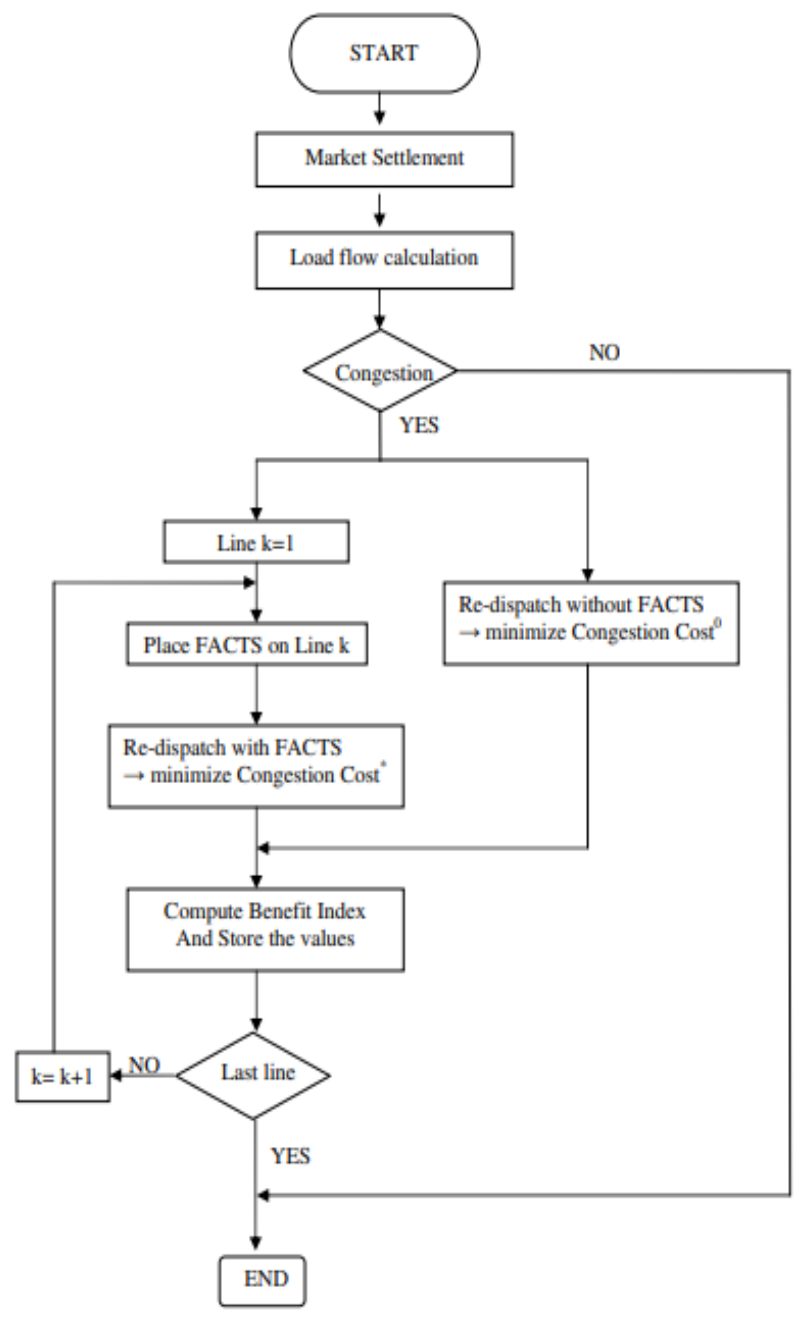

Fig 2. Flow chart for procedure of choosing optimal location of FACTS

\section{Results of Transmission Pricing Parameters for IEEE 14 bus Case Study}

Results gained by implementing the proposed approach to the IEEE 14-bus renumbered test system are given in this section. Fig. 4 illustrates the single line diagram of the test system. Table IA and IB show the basic operating condition and regulated bus data of the network. The participation factors of generators are adopted to deal to their initial MW. Loads are considered to be autonomous of bus voltages $(\mathrm{pi}=\mathrm{qi}=0)$ and increased consistently to verify the strength limit. Table II is the system condition at the security limit obtained by a mechanism in [14]. TCSC and SVC were adopted to develop security margin and energy profile of the operation. The voltage magnitude limits of regulated buses are set to 1 and $1.1 \mathrm{pu}$ for lower and upper bounds. 
TABLE IA

ESTIMATION OF INITIAL OPERATING

CONDITION OF THE 14-BUS RENUMBERED NETWORK

\begin{tabular}{lllll}
\hline \hline \multirow{2}{*}{$\begin{array}{l}\text { Bus } \\
\text { Number }\end{array}$} & Voltage & \multicolumn{3}{c}{ Bus Power } \\
\cline { 2 - 5 } & Mag (pu) & Ang & P(MW) & Q (MVAR) \\
\hline 1 & 1.08 & 0 & 0 & 0 \\
2 & 1.08 & 0 & 157.7 & 0 \\
3 & 1.08 & 0 & 214.1 & 0 \\
4 & 1.08 & 0 & 98 & 0 \\
5 & 1.09 & 0 & 0 & 0 \\
6 & 1 & 0 & 167.8 & 31.6 \\
7 & 1 & 0 & 102.9 & 54.9 \\
8 & 1 & 0 & 0 & 0 \\
9 & 1 & 0 & 57.8 & 16.8 \\
10 & 1 & 0 & 19 & 5.8 \\
11 & 1 & 0 & 53.5 & 7.8 \\
12 & 1 & 0 & 16.1 & 6.6 \\
13 & 1 & 0 & 27.3 & 5.8 \\
14 & 1 & 0 & 25.4 & 10 \\
\hline \multicolumn{5}{l}{} \\
\hline \hline
\end{tabular}

TABLE IB

REGULATED BUS DATA

\begin{tabular}{lllll}
\hline \hline \multirow{3}{*}{ Bus } & MVAR & & MW \\
& Limits & & Limits \\
\cline { 2 - 5 } & Min. & Max. & Min. & Max \\
\hline 2 & -50 & 100 & 0 & 200 \\
3 & -50 & 100 & 0 & 300 \\
4 & -50 & 100 & 0 & 200 \\
5 & -6 & 40 & 0 & 0 \\
\hline \hline
\end{tabular}

Both lines and load buses are initial candidates of optimization strategy to locate TCSCs and SVCs. The problem solution has been identified after running SA with a consolidation of SQP method, so as given in Table III, eight TCSCs and two SVCs have been established. With this excellent solution for deployment of TCSC and SVC, SM improves from 0.0209 to 0.1605 . Also, as expressed in Table IV, without TCSC and SVC, lines 4-11 and 4-13 will be overloaded using base load from Table IA. Using TCSCs and SVCs in Table III, line congestion has been taken out for lines 4-11 and 413 as stated in Table IV. The calculation of objective work during development process is given in Fig. 5. Because of the capability of SA, the development strategy has come to the overall greatest solution by running a zigzag convergence line and departing from the local smallest.
TABLE II

SYSTEM CONDITION AT VOLTAGE STABILITY LIMIT WITH AND WITHOUT TCSC / SVC

\begin{tabular}{|c|c|c|c|c|c|c|}
\hline \multirow{3}{*}{ 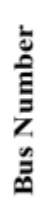 } & \multicolumn{2}{|c|}{ Voltage Mag (pu) } & \multicolumn{4}{|c|}{ Bus Power } \\
\hline & \multirow{2}{*}{$\begin{array}{c}\text { Without } \\
\text { TCSC } \\
\text { / SVC }\end{array}$} & \multirow{2}{*}{$\begin{array}{c}\text { With } \\
\text { TCSC } \\
\text { / SVC }\end{array}$} & \multicolumn{2}{|c|}{$\begin{array}{l}\text { Without } \\
\text { TCSC / SVC }\end{array}$} & \multicolumn{2}{|c|}{$\begin{array}{l}\text { With } \\
\text { TCSC / SVC }\end{array}$} \\
\hline & & & MW & MVAR & MW & MVAR \\
\hline 1 & 1.08 & 1.08 & 32.16 & 49.24 & 49.77 & 87.83 \\
\hline 2 & 1.08 & 1.08 & 161.07 & 81.6 & 187.84 & 66.13 \\
\hline 3 & 1.08 & 1.08 & 218.68 & -10.79 & 255.02 & -18.5 \\
\hline 4 & 1.043 & 1.036 & 100.09 & 100 & 116.73 & 100 \\
\hline 5 & 1.09 & 1.09 & 0 & 24.69 & 0 & 18.12 \\
\hline 6 & 0.994 & 0.991 & 171.27 & 32.25 & 199.78 & 37.62 \\
\hline 7 & 0.974 & 0.975 & 105.03 & 56.04 & 122.51 & 65.36 \\
\hline 8 & 1.05 & 1.061 & 0 & 0 & 0 & 0 \\
\hline 9 & 1.013 & 1.038 & 59 & 17.15 & 68.82 & 20 \\
\hline 10 & 0.996 & 1.034 & 19.39 & 5.92 & 22.62 & 6.91 \\
\hline 11 & 0.982 & 1.011 & 54.61 & 7.96 & 63.7 & 9.29 \\
\hline 12 & 1.006 & 0.994 & 16.43 & 6.74 & 19.17 & 7.86 \\
\hline 13 & 1.003 & 0.971 & 27.86 & 5.92 & 32.5 & 6.91 \\
\hline 14 & 0.972 & 0.965 & 25.93 & 10.21 & 30.24 & 11.91 \\
\hline \multicolumn{7}{|c|}{$S M$ without TCSC/SVC 0.0209} \\
\hline
\end{tabular}

TABLE III

THE AMOUNT AND LOCATION OF TCSC AND SVC

\begin{tabular}{lllll}
\hline \hline $\begin{array}{l}\text { TCSC } \\
\text { location }\end{array}$ & $\begin{array}{l}\text { SVC } \\
\text { location }\end{array}$ & $\begin{array}{l}\text { Line } \\
\text { compensation }\end{array}$ & $\begin{array}{l}\text { SVC } \\
\text { susceptance } \\
\text { in pu }\end{array}$ \\
$\begin{array}{lllll}\text { Initial } \\
\text { bus }\end{array}$ & $\begin{array}{l}\text { Final } \\
\text { bus }\end{array}$ & $\begin{array}{l}\text { Bus } \\
\text { Number }\end{array}$ & by TCSC in \% & in pu \\
\hline 1 & 2 & 10 & -55.2483 & 0.5 \\
2 & 7 & 13 & -35.4469 & -0.25 \\
1 & 7 & - & -63.9508 & - \\
4 & 11 & - & 15.71141 & - \\
4 & 12 & - & -67.1885 & - \\
9 & 10 & - & -64.7189 & - \\
10 & 11 & - & -65.0804 & - \\
12 & 13 & - & -62.5375 & - \\
\hline \hline
\end{tabular}

TCSC: Negative means capacitive and positive means inductive SVC: Negative means inductive and positive means capacitive 


\section{TABLE IV \\ COMPARISON OF LINE POWERS BASED ON \\ DATA IN TABLE IA WITH AND \\ WITHOUT TCSC / SVC}

\begin{tabular}{|c|c|c|c|c|c|}
\hline \multirow{2}{*}{$\begin{array}{l}\text { Line } \\
\text { Number }\end{array}$} & \multirow{2}{*}{$\begin{array}{l}\text { Initial } \\
\text { bus }\end{array}$} & \multirow{2}{*}{$\begin{array}{l}\text { Final } \\
\text { bus }\end{array}$} & \multirow{2}{*}{$\begin{array}{l}\text { Power } \\
\text { Limits } \\
\text { (MW) }\end{array}$} & \multicolumn{2}{|c|}{ Lines Active Power (MW) } \\
\hline & & & & $\begin{array}{l}\text { Without } \\
\text { TCSC/SVC }\end{array}$ & $\begin{array}{l}\text { With } \\
\text { TCSC/SVC }\end{array}$ \\
\hline 1 & 2 & 3 & 150 & 100.74 & 115.27 \\
\hline 2 & 3 & 6 & 150 & 111.45 & 96.33 \\
\hline 3 & 1 & 2 & 150 & 39.95 & 69.35 \\
\hline 4 & 2 & 7 & 150 & 109.12 & 117.05 \\
\hline 5 & 2 & 6 & 150 & 108.68 & 84 \\
\hline 6 & 1 & 7 & 150 & 71.04 & 102.65 \\
\hline 7 & 6 & 7 & 150 & 9.8 & 18.55 \\
\hline 11 & 4 & 11 & 60 & 62.04 & 54.36 \\
\hline 12 & 4 & 12 & 45 & 20.13 & 28.98 \\
\hline 13 & 4 & 13 & 45 & 46.19 & 37.56 \\
\hline 16 & 9 & 10 & 45 & 14.05 & 21.18 \\
\hline 17 & 9 & 14 & 45 & 5.26 & 5.88 \\
\hline 18 & 10 & 11 & 45 & 5.01 & 1.65 \\
\hline 19 & 12 & 13 & 45 & 3.54 & 11.95 \\
\hline 20 & 13 & 14 & 45 & 21.02 & 20.5 \\
\hline
\end{tabular}

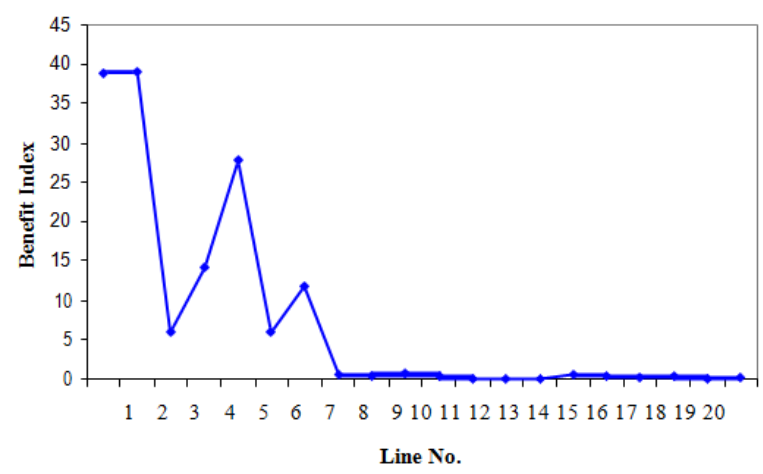

Fig 3. Placement of FACTS

\section{Conclusion}

Re-dispatching of generation in a network with persistent congestion may be referred to as a smallterm solution. The great-term solution may be to upgrade congested aisles, develop new transmission systems, or run the prevailing infrastructure more by FACTS devices. Owing to the poor installation times, resilience to power flow regulation and contraction of prices over the years FACTS devices are becoming prevalent. Commercial pressures on achieving higher profits from existing assets represent a significant aspect of FACTS. Using series compensation FACTS can reduce congestion. In the other market models it has been demonstrated that FACTS can cut down the value of re-dispatched power and the cost of bottleneck. Placement these devices in the network can estimate for most net pay. Whilst FACTS are employed in this study for congestion control, we need them for development of effective operation of the network by extending the margins for transient stability and voltage stability. The economic appraisal for placing FACTS has merely affected the static problems, but we should have it in perceiving that new advances are achievable.

The dispatch schedule after re-dispatch has been excellent from a practical situation of consideration and the $\mathrm{N}-0$ condition. We have demonstrated both the 14 bus and 32 bus structures for N-1 principle. Contingency analysis is a powerful part of system surveillance. An AC load movement is the standard medium to run for the contingency analysis, but because of the limited speed of the calculations and the enormous volume of situations to be investigated, we need the DC flow. This study includes a unique combinatorial transmission pricing method. Being honest and integrating various transmission services costs in the estimating process are of its principal aspects.

After applying FACTS Device as a TCSC AND SVC, this study presents computation of transmission pricing for a case review of standard IEEE 9 bus and IEEE 14 bus system as an essential part of simulator developed for deregulated power trading. Here the FACTS device location considered economic saving function, so we can work out that with aid of TCSC AND SVC congestion gets reduces, taxes are reduces also it cut down the transmission pricing. Formulation can make clear the legitimacy of the method, examine the usage tax $\&$ offer correct economic incentive for productive operation, supply \& future progress of transmission network. We get the congestion cost saving depending on the time span that TCSCs served. The results indicated that in one line removal process the cost saving figure is $1,081.93 \$ / \mathrm{hr}$. In two lines removal process, we got the reimbursement rate to be $1,138.93 \$ / \mathrm{hr}$. We got the reimbursement rate in generation reduction process to be $1,074.43 \$ / \mathrm{hr}$.

Study results show using TCSC, in congested network, may be more valuable than SVC. The amount of used TCSCs in situations of probability analysis appeared in four TCSCs. Different quantities of SVCs were employed depending on the probability situation. 
References:

[1] A.M. Leite da Silva and G.P. Alvarez, "Operating reserve capacity requirements and pricing deregulated markets using probabilistic technique", IET Gener. Transm. Distrib., 2007, 1, (3), pp.439-446.

[2] S.Jeyasankari, J.Jeslin Drusila Nesamalar, "Transaction Cost Allocation in Deregulated Power System Using An Analytical Method", IEEE Trans Power System, pp. 1090 - 1096 , November 2013.

[3] Amirsaman Arabali, Seyed Hamid Hosseini, Moein Moeini-Aghtaie, "Pricing of Transmission Services: An Efficient Analysis Based on Fixed and Variable Imposed Costs", IEEE Trans Power System, November 2012.

[4] R. Reta and A. Vargas, "New Price System to Mitigate Marginal Price Volatility In Electricity Markets", IEEE Latin America Trans Power System vol. 9, no. 5, pp. 793-799, September 2011.

[5] G. A. Orfanos, G. T. Tziasiou , "Evaluation of Transmission Pricing Methodologies for Pool Based Electricity Markets " , IEEE Trans Power System vol. 15 , no. 4 , pp. 1218 - 1224 , November 2011.

[6] Sandip Chanda,Abhinandan De, " Application of Particle Swarm Optimization for relieving Congestion in Deregulated Power System", IEEE Transaction on Power Systems, pp.837840,November 2011.

[7] Rony Seto Wibowo, Naoto Yorino, Mehdi Eghbal, "FACTS Devices Allocation for Congestion Management Considering Voltage Stability by Means of MOPSO", IEEE T \& D 2009.

[8] M. Judite Ferreira, Zita A. Vale, " A Congestion Management and Transmission Price Simulator for competitive Electricity markets", IEEE Transaction on Power Systems, pp.1-8, 2007.

[9] Diego mejia-Giraldo,James McCalley, “ Adjustable Decision for reducing the Price Robustness of Capacity Expansion Planning", IEEE Transaction on Power Systems, Vol. 29, no. 4, pp.1573-1582,July 2014.

[10] Teo Guler, George Gross and Ron Coutu, “ On the Economics of Power System Security in Multi-Settlement Electricity Markets", IEEE Transaction on Power Systems, vol.25, No. 1, pp.284-295,February 2010.
[11] Robert Baker, P. Eng., Dr. Xiaomiao Wu, P.Eng, Dr. Ashikur Bhuiya,P.Eng., “ Transmission Loss Cost Reconciliation In Alberta's Deregulated Electric Market", pp.1277-1280, 2007.

[12] V. Sarkar and S. A. Khaparde, "Introduction to Multidimensional financial Transmission Rights", IEEE Transaction on Power Systems, Vol.23, No.1, pp.837-840, February 2008.

[13] V. Sarkar nad S.A. Khaparde, "A Comprehensive Assessment of the Evolution of Financial Transmission Rights", IEEE Transaction on Power Systems, Vol.23, No.4, pp.837-840, November 2008.

[14] N.G.Hingorani, L. Gyugyi " Understanding FACTS: Concepts and Technology of Flexible AC Transmission Systems", IEEE Power Engineering Society, IEEE press, Delhi 2001.

[15] M. Marmiroli, M. Tanimoto, Y. Tsukamoto, and R. Yokoyama, "Market Splitting Algorithm for Congestion Management in Electricity Spot Market," Proceeding of the WSEAS PE, vol. 6, pp. 338-344, 2006.

[16] Baseem Khan, Ganga Agnihotri," An Approach for Transmission Usage \& Loss Allocation by Graph Theory", Proceeding of the WSEAS PE, Volume 9, pp. 44 -53,2014.

[17] Mariia Ruda, Taras Boyko, Camillo La Mesa, Computer Simulation of the Influence of Wind Power Plants on The Compartments of The Complex Landscape System by The Method of Life Cycle Assessment, Pages 34-50, Engineering World, Volume 2, 2020

\section{Creative Commons Attribution License 4.0 (Attribution 4.0 International, CC BY 4.0)}

This article is published under the terms of the Creative Commons Attribution License 4.0 https://creativecommons.org/licenses/by/4.0/deed.en_US 